\title{
Análise e indexação de imagens na rede Flickr
}

\author{
Rafael Alves de Oliveira \\ Doutorando; Universidade Federal da Paraíba (UFPB), João Pessoa, PB, Brasil; \\ rraffael@gmail.com \\ Luciane Paula Vital \\ Doutoranda; Universidade Federal de Santa Catarina (UFSC), Florianópolis, SC, Brasil; \\ lucianepv@yahoo.com.br
}

\begin{abstract}
Resumo: O artigo apresenta um breve panorama sobre a disseminação e democratização da internet colaborativa, e de como esse processo popularizou o uso da imagem em suporte digital. Faz uma breve análise sobre a rede social Flickr, identificando seus objetivos, suas ferramentas, e alguns dos estudos relativos à sua usabilidade no âmbito da Ciência da Informação. Delimita a abordagem para as imagens armazenadas na rede, propondo um estudo qualitativo em torno da indexação livre realizada por seus usuários. Aplica a metodologiaestabelecida em estudo anterior como a mais apropriada para indexação de imagens fotográficas em ambiente web, comparando os resultados obtidos com a indexação livre realizada pelos usuários.
\end{abstract}

Palavras-chave: Imagem. Indexação de imagens. Flickr. Redes sociais. Indexação social.

\section{Introdução}

A década de 2001 a 2010 foi testemunha do surgimento de um novo conceito de uso da internet. A possibilidade de publicação e tratamento livre de informações por parte de seus usuários tornou-se a característica fundamental deste novo modelo, que, embora não seja um consenso, os estudiosos nomearam de Web 2.0. Em alguma medida, pode-se dizer que a criação das redes sociais foi uma consequência natural desse fato, e que a aceitação dessas por parte de uma grande parcela dos usuários da internet é um reflexo de como este modelo se estabeleceu, e tende a se aprimorar.

Essas novas ferramentas disseminaram o conceito e democratizaram o uso de um suporte informacional bastante peculiar: a imagem, que migrou dos 
álbuns de fotografias e das molduras de parede para o suporte digital, podendo agora ser acessada a qualquer instante, de qualquer lugar do planeta.

[...] com as novas tecnologias de comunicação e informação uma nova fase inicia-se, e nesta, as imagens são disponibilizadas livremente pelos usuários na internet. Essa liberdade de publicação, naturalmente, impeliu os métodos de tratamento e recuperação para essa mesma ideia. Agora o usuário não só pode publicar as imagens como também categorizá-las. Esse boom de imagens disponibilizadas iniciou-se com o surgimento das redes sociais. A sociedade aderiu a esta nova forma de interagir, e as redes cresceram e popularizaram-se significativamente ao longo de poucos anos. À medida que as ferramentas destas redes se desenvolviam com o avanço dos seus servidores, as redes podiam armazenar cada vez mais informações. A publicação livre de imagens foi apenas um passo natural nesse desenvolvimento. (OLIVEIRA, 2011, p. 2).

Partindo desse pressuposto, fica evidente que uma problemática tende a surgir com esse avanço, e diz respeito especificamente à maneira como estas imagens serão tratadas e recuperadas. Na literatura científica de Ciência da Informação ainda não existe um acordo sobre como as imagens devem ser tratadas, pois diversos fatores implicam nessa análise, incluindo o tipo de imagem (pinturas, fotografias, etc.) e o suporte no qual se encontra. Entretanto, alguns modelos bem construídos e eficientes podem ser encontrados, como o de Manini (2002) e Rodrigues (2007).

No trabalho intitulado Metodologias para indexação de imagens fotográficas em ambiente web (OLIVEIRA, 2011) são apresentados e analisados os elementos propostos e o comportamento de três das metodologias para indexação de imagens mais citadas na literatura científica da área da Ciência da Informação, visando identificar aquela que poderia ser considerada mais adequada à aplicação em imagens fotográficas coletadas em ambiente web. Este estudoanalisa, dentre outras, a metodologia proposta por Rodrigues (2007), na qual o autor revela que uma imagem não apenas mostra, mas também representa algo, que pode não necessariamente ter uma relação direta aos objetos apresentados. Devido a isso, entende-se que uma imagem terá dois níveis ou sentidos principais: o denotativo, que se refere "[...] àquilo que a imagem representa com 'certa precisão', no seu sentido real” (RODRIGUES, 2007, p.69), e o conotativo,referente àquilo '“[...] que a imagem pode 'interpretar' em 
um determinado contexto, em um sentido figurado e simbólico".(RODRIGUES, 2007, p. 69). A partir dessa constatação, Rodrigues (2007) estabelece que devem ser considerados os seguintes elementos para uma análise apropriada:

a) descrição física, ou o "[...] formato e tamanho da imagem fotográfica, tipo de suporte, autor, transformações ocorridas a partir do original etc". (RODRIGUES, 2007, p.75);igo de periódico NBR 6022/03;

b) composição, ao considerar “[...] tipo de luz, nível de nitidez dos assuntos, ponto de vista do fotógrafo, profundidade de campo e hierarquia das figuras, enquadramento etc".(RODRIGUES, 2007, p. 75);

c) contexto arquivístico, ou os locais e fatos, históricos ou não, correspondentes àquela fotografia;

d) sentidos denotativos e conotativos, correspondendo ao que imagem mostra e ao que ela representa, respectivamente;

e) tematização, ao atribuir a imagem a um contexto diferente do que é mostrado, mas que possui relação direta aos elementos denotativos apresentados.

Após traçar um quadro comparativo observou-se que, para uma análise de imagens coletadas em ambiente web, a metodologia proposta por Rodrigues (2007) pode ser considerada a mais apropriada, já que enfatiza os elementos conotativos identificados numa imagem, considerando-se que uma imagem coletada na internet tem grande possibilidade de não apresentar informações técnicas referentes a esta.

A partir das constatações obtidas neste estudo, buscaremos obter um breve panorama sobre a indexação realizada livremente pelos usuários de redes sociais por meio da aplicação prática da metodologia de Rodrigues (2007) e da interpretação dos dados obtidos. O banco de imagens escolhido para a pesquisa foi a rede Flickr, por se tratar de uma rede social amplamente utilizada e ter seu foco no compartilhamento de recursos visuais. Desde já delimitaremos o objeto de estudo apenas às imagens armazenadas pela rede Flickr, embora a rede atualmente permita também o compartilhamento de vídeos. 


\section{Flickr: uma breve análise}

O Flickr é uma rede de compartilhamento de imagens hospedada na internet. O Flickr, segundo os próprios idealizadores,propõe novas formas para organizar fotografias, que poderão ser acessadas livremente por qualquer pessoa.

Parte da solução é tornar colaborativo o processo de organizar fotos [...] No Flickr, é possível permitir que seus amigos, família e outros contatos organizem suas coisas - não apenas adicionem comentários, mas também notas e tags. [...] E, à medida que essas informações crescem como metadados, você poderá encontrar as coisas facilmente mais tarde, uma vez que toda essa informação pode ser buscada. (FLICKR, 2014c, documento eletrônico sem paginação).

Embora seja considerado uma rede social, o Flickr permite que mesmo aqueles que não possuam cadastro na base tenham acesso às imagens disponibilizadas. No entanto, o usuário tem a liberdade de restringir o acesso a algumas de suas fotografias apenas àqueles usuários que lhes forem mais convenientes. O Flickr é um claro exemplo de ambienteque permite a utilização e o emprego daquilo que a literatura científica nomeou de folksonomias,

[...] que podem ser definidas como sistemas orgânicos baseados na atribuição livre e pessoal de [termos] à informações ou objetos visando à organização e recuperação. O neologismo folksonomia formado pelas palavras, em inglês, folks (pessoas) e taxonomy (taxonomia) - foi cunhado [...] como forma de expressar contraposição às classificações do conhecimento tradicionais, elaboradas por especialistas e construídas baseando-se em arranjos hierárquicos. (GUEDES; DIAS, 2010, p.48).

No Flickr podemos identificar dois tipos de usuários: aqueles que possuem cadastro na base e, portanto, podem publicar fotos e se utilizar de todas as ferramentas que o Flickr oferece; e aqueles que não possuem qualquer vínculo com o sistema, apenas o utilizam para fazer pesquisas no conjunto de fotografias disponibilizadas para consulta pública. Ao primeiro tipo, chamaremos de usuário regular; ao segundo, usaremos a definição usuárioconsultor. 
Apesar de ser descrito como um ambiente que utiliza folksonomias (HIDDERLEY; RAFFERTY, 2007), na prática o Flickr não permite que a indexação seja feita livremente pelo usuário-consultor, como acontece na maioria desses ambientes. Apenas o usuário regular pode fazê-lo e, no máximo, outros usuários regulares que receberam do proprietário das imagens uma permissão para tanto. Esses poderão indexar as imagens utilizando-se do recurso detagging (do inglês, etiquetagem), que consiste na atribuição de termos que representem os conteúdos informacionais disponibilizados na web.

As tags são como palavras-chave ou títulos que você adiciona a uma foto para facilitar encontrá-la posteriormente. Você pode criar uma tag para uma foto com frases como "Catarina caminhada trilha montanha Yosemite." Posteriormente, se você procurar por imagens de Catarina, bastará clicar nessa tag e obter todas as fotos marcadas dessa maneira. (FLICKR, 2014a, documento eletrônico sem paginação).

As tags atribuídas a determinado conteúdo servirão como uma referência conceitual aos usuários que terão acesso posterior àquela informação. No caso do Flickr, o usuário regular disponibiliza a imagem na base e atribui, a partir da sua interpretação, termos que representem a imagem. Em seguida, o usuárioconsultor, ou outros usuários regulares, poderão pesquisar as imagens disponibilizadas através de palavras-chave e a base naturalmente utilizará as tags atribuídas a cada imagem como ferramenta de busca. Alguns autores preferem o termo indexação social para identificar esse processo.

Cada imagem pode ter um máximo de 75 tagsatribuídas a ela. No entanto, o usuário regular tem, além das tags, outra forma de descrever uma imagem: o texto. Este pode conter, como sugere o próprio Flickr (2014a), a história da fotografia e/ou notas explicativas sobre esta. É importante ressaltar que o Flickr não se utiliza exclusivamente das tags atribuídas às imagens para fazer a recuperação, mas também de termos livres contidos nas descrições. $\mathrm{Na}$ hora da busca, o usuário pode escolher entre pesquisar apenas nas tags, ou por meio de termos livres, incluindo assim os textos.

Tags, ao contrário de termos de indexação (descritores); geralmente utilizados em unidades de informação, não possuem um mediador 
que as controle. O Flickr diferencia-se de outros ambientes que utilizam folksonomias por estabelecer que apenas o usuário regular possua tal liberdade (embora alguns ambientes que empregam folksonomiastambém utilizem esse recurso), provavelmente como uma forma de minimizar tags 'inúteis'. O Flickr também propõe uma lista de "hot tags", ou "etiquetas quentes", que consistem numa lista das tags mais utilizadas pelos usuários regulares. Essas são, possivelmente, estratégias desenvolvidas pelos administradores da base para aprimorar as formas de indexação, ou tagging, das imagens.

Problemas no processo de indexação e as consequências na recuperação das imagens foram identificados por alguns autores. Rafferty e Hidderley (2007), numa pesquisa controlada, mostram como os índices de revocação podem variar imensamente de acordo com o termo atribuído, quando explicam que

A [...] tag [...] "casamento" recuperou 795.280 imagens, quando utilizada no Flickr em 14 de fevereiro de 2006, sugerindo que este seria um exemplo de uma tag talvez ampla demais. A [...] tag "Iijsselmeer" recuperou apenas uma imagem, e é um exemplo de uma tag que talvez seja específica demais para o propósito de pesquisa pública. (RAFFERTY; HIDDERLEY, 2007, p. 403, tradução nossa) ${ }^{1}$.

No exemplo mostrado, o termo WEDDING é considerado muito geral pelos autores, recuperando um número de imagens considerado absurdo. Já o termo IIJSSELMEER, segundo os autores, é específico demais para uma imagem disponibilizada numa base para uso público, recuperando apenas uma imagem. Analisar os resultados da recuperação, no entanto, não é suficiente para deduzir que a causa do problema seja a forma como os usuários indexam as imagens no Flickr. Percebemos, inclusive, que há um interesse por parte dos próprios administradores em educar os usuários a controlar os termos utilizados. É possível que, apesar de os índices de recuperação no Flickr não terem sido considerados satisfatórios pelos autores, os termos utilizados pelos usuários na atribuição de tags representem de forma efetiva os elementos apresentados na imagem. 
Partindo desse impasse, coletamos algumas imagens no Flickr para analisá- las com base na metodologia proposta por Rodrigues (2007), anteriormente considerada a mais adequada para o ambiente web dentre as metodologias para representação imagética encontradas, e comparar os resultados obtidos com as tags atribuídas pelos usuários. Assim, é possível perceber se a indexação de imagens que está sendo realizada por meio das ferramentas da Web 2.0 condiz qualitativamente com aquela indexação proposta pelos estudiosos da área.

\section{Procedimentos metodológicos}

Entendemos este estudo como sendo de caráter qualitativo, já que não buscamos uma coleta precisa de dados estatísticos, mas uma análise interpretativa, baseada essencialmente no que a literatura científica diz a respeito do tema. Através deste estudo, buscamos compreender um pouco mais sobre as modalidades de indexação imagética.

O Flickr possui uma quantidade de fotos armazenadas que cresce de forma rápida e significativa. Dessa forma, percebemos de imediato que o Flickr constitui um universo de amplitude infinita.

Sendo esta pesquisa de caráter qualitativo, recorremos a Gil (2008) para obter alguns esclarecimentos a esse respeito. $\mathrm{O}$ autor explica, dentre outras formas de coletar amostras, que a amostragem por acessibilidade ou por conveniência

[...]constitui o menos rigoroso de todos os tipos de amostragem. Por isso mesmo é destituída de qualquer rigor estatístico. O pesquisador seleciona os elementos a que tem acesso, admitindo que estes possam, de alguma forma, representar o universo. Aplica-se este tipo de amostragem em estudos exploratórios ou qualitativos, onde não é requerido elevado nível de precisão. (GIL, 2008, p. 94, grifo nosso).

Dessa forma, buscamos tornar possível a análise da metodologia em ambiente web,mesmo admitindo a infinidade de imagens que podem ser encontradas nesse contexto.Devemos destacar, antes de explanar os 
procedimentos, que, visando delimitar o campo de estudo, fica estabelecido que apenas as tags atribuídas na língua portuguesa serão consideradas na análise. Tags em quaisquer outras línguas serão desconsideradas, assim como aquelasque apresentem composição confusa devido a possíveis erros de grafia.

Em vista disso, foram realizados os seguintes procedimentos para a coleta das imagens utilizadas neste estudo:

a) optamos por fazer a pesquisa como usuário consultor, uma vez que, desta forma, o cadastro na base não interfere significativamente na busca;

b) na página inicial do Flickr, utilizamos os termos TAGS (para realizar a pesquisa inicial de imagens, por se tratar de um termo bastante amplo, de certa forma desprovido de qualquer conceituação, e, como já visto, muito utilizado na base); e BRASIL (para delimitar ao máximo as imagens recuperadas à imagens com tags em língua portuguesa). Dessa forma, as imagens foram recuperadas de forma aleatória no que diz respeito à sua temática;

c) após a pesquisa inicial, a base dá a possibilidade de escolha entre a pesquisa em todos os textos atribuídos a uma imagem ou apenas em suas tags. Visando uma maior generalidade de imagens recuperadas, optamos por permanecer na busca realizada em todos os textos;

d) tendo em vista uma maior aleatoriedade na coleta, foi selecionada uma imagem de cada página dos resultados de busca, sendo analisadas quatro imagens ao final;

e) buscando uma conceituação diferenciada e equilibrada nas imagens coletadas, duas dessas foram selecionadas por conterem seres humanos, e as duas restantes por não conterem humanos representados.

Coletados os dados, aplicamos a cada imagem a metodologia proposta por Rodrigues (2007) e, em seguida, comparamos os resultados com as tags atribuídas, visando analisar qualitativamente a indexação realizada pelos usuários. 


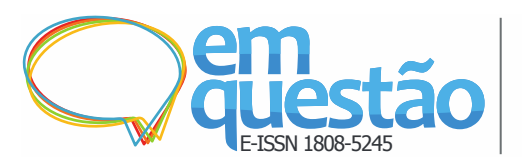

\section{Resultados obtidos}

Utilizando os procedimentos metodológicos estabelecidos para a coleta e análise das imagens no Flickr, obtivemos as seguintes imagens:

Figura 1 - Praia de Jurerê - Florianópolis, SC

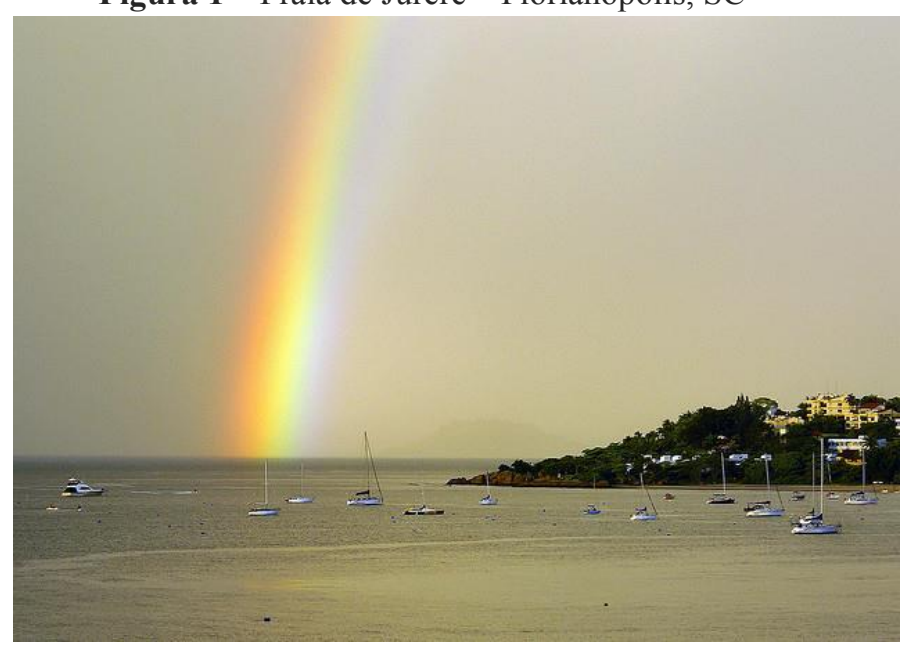

Fonte: Flickr(2014b).

$\mathrm{Na}$ área reservada para o texto descritivo da imagem, o autor indica que esta imagem refere-se à Praia de Jurerê, localizada em Florianópolis, estado de Santa Catarina. As tagsatribuídas a esta imagem foram, em ordem de aparição:

Quadro 1 - Tags atribuídas à Figura 1 por usuário da redeFlickr

\begin{tabular}{|c|c|}
\hline Rainbow & top20travel \\
\hline Arco-íris & A Plus Photo \\
\hline Jurerê & The World Throgh a Lens \\
\hline Florianópolis & Platinum Photo \\
\hline Santa Catarina & Geo-tagged \\
\hline Brasil & 100v+10f \\
\hline Brazil & Novas Jurerê \\
\hline
\end{tabular}

Fonte: elaborado pelos autores

Aplicando a metodologia de Rodrigues (2007), chegamos à seguinte análise: 
Quadro 2 - Aplicação da metodologia de Rodrigues (2007) para a Figura 1

\begin{tabular}{|c|c|c|}
\hline DESCRIÇÃO FÍSICA & COMPOSIÇÃO & CONTEXTO ARQUIVÍSTICO \\
\hline--- & -- & $\begin{array}{c}\text { Jurerê } \\
\text { Florianópolis } \\
\text { Santa Catarina }\end{array}$ \\
\hline SENTIDO DENOTATIVO & SENTIDOS CONOTATIVOS & TEMATIZAÇÃO \\
\hline Praia & Tranquilidade & Meteorologia \\
Chuva & & \\
\hline
\end{tabular}

Fonte: elaborado pelos autores.

Através da metodologia de Rodrigues (2007), atribuímos oito termos que poderiam recuperar essa imagem. No Contexto Arquivístico, os termos JURERÊ, FLORIANÓPOLIS e SANTA CATARINA referem-se à procedência da imagem, ou seja, ao local apresentado na fotografia, e, consequentemente, onde esta foi produzida. No Sentido Denotativo, os termos PRAIA, ARCO-ÍRIS e CHUVA representam os objetos identificados pelos autores, enquanto nos Sentidos Conotativos o termo TRANQUILIDADE expressa a sensação transmitidaaos autores no momento da observação. Entretanto, por se tratar de um elemento essencialmente subjetivo, outros termos podem ser atribuídos por observadores diferentes. Por fim, no campo Tematização, o termo METEOROLOGIA reproduz um enquadramento temático feito pelos autores diante dos elementos objetivos apresentados. Apesar desse enquadramento temático ser subjetivo, é mais fácil apontar os elementos que levaram a tal determinação, que, no caso da fotografia em questão, os elementos que levaram à atribuição das tags PRAIA e CHUVA. Entretanto, da mesma forma que os Sentidos Conotativos, a Tematização pode variar de um observador para outro.

Como ficou claro nas tags associadas a essa imagem, alguns termos não correspondem à língua portuguesa, enquanto outros apresentam composição confusa e, portanto, deverão ser desconsiderados. Traçando um comparativo entre as tagsválidas e os termos adquiridos por meio da metodologia, temos: 
Quadro 3 - Comparação entre as tagsconsideradas válidas e os resultados obtidos na análise

\begin{tabular}{|c|c|}
\hline $\boldsymbol{T A G S}$ & TERMOS \\
\hline Arco-íris & Jurerê \\
\hline Jurerê & Florianópolis \\
\hline Florianópolis & Santa Catarina \\
\hline Santa Catarina & Praia \\
\hline Brasil & Arco-íris \\
\hline Novas Jurerê & Chuva \\
\hline--- & Tranquilidade \\
\hline--- & Meteorologia \\
\hline
\end{tabular}

Fonte: elaborado pelos autores

Dentre as tags consideradas válidas para esta pesquisa, apenas quatro coincidem com os termos adquiridos através da metodologia. Termos considerados indispensáveis na indexação desta imagem, como PRAIA, não aparecem nas tags. A tag BRASIL, por sua vez, apesar de corresponder a um dos critérios de busca para a presente pesquisa e ser relevante para situar a localização do ambiente apresentado na ilustração, é excessivamente genérica para descrever, por si só, essa imagem, enquanto NOVAS JURERÊ parece ser uma indicação individual de localização para o próprio autor da fotografia, não podendo ser considerado relevante para descrevê-la.

Avançando para a próxima página de busca, coletamos a seguinte imagem: 


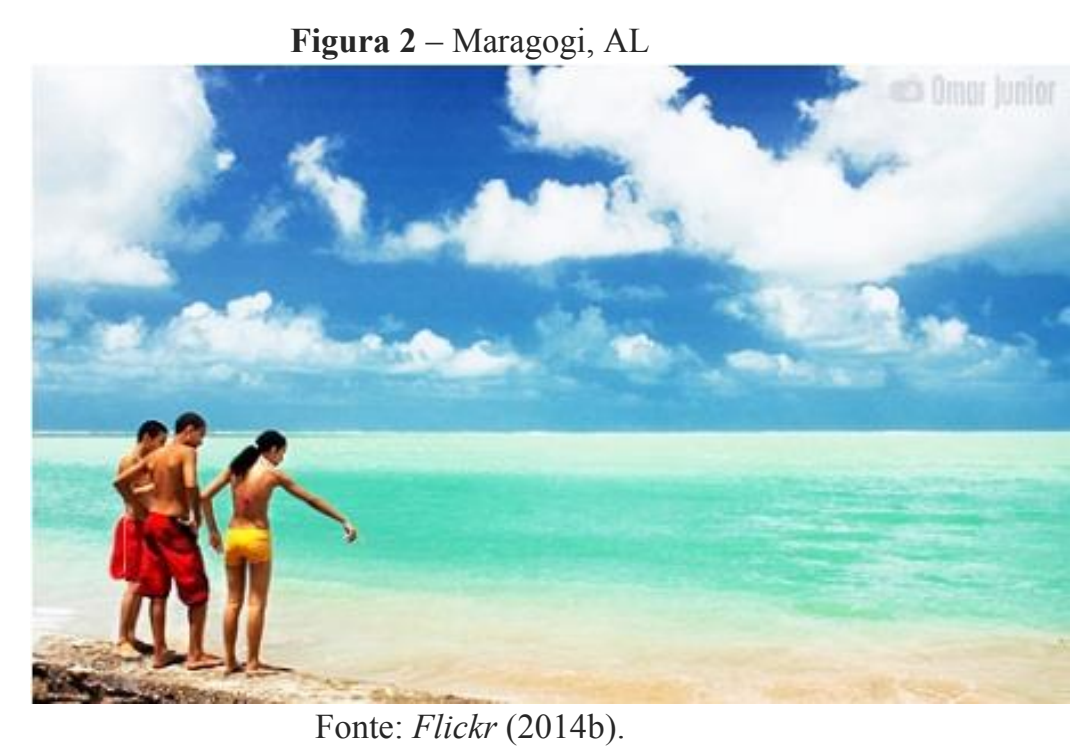

Nesta imagem é possível identificar um grupo de jovens observando o mar. Segundo as informações do autor da fotografia, ela foi tirada na Praia de Peroba, em Maragogi, Estado de Alagoas. Diversas tags referenciam ess imagem, como as listadas a seguir: 
Quadro 4 - Tags atribuídas à Figura 2por usuário da rede Flickr

\begin{tabular}{|c|c|c|}
\hline Colors & Miramar & Caribe \\
\hline Color & Boa viagem & Brasileiro \\
\hline Maragogi & Contraste & O Caribe brasileiro \\
\hline Alagoas & Cores & Viagem \\
\hline Peroba & Fortes & Dicas \\
\hline Praia & Vibrantes & Ficar \\
\hline Beach & Viva & Salinas \\
\hline Red & Paraíso & Férias \\
\hline Yellow & Paradise & Piscinas \\
\hline Mar & Geotagged & Naturais \\
\hline Céu & Beaches & Maceió \\
\hline Azul & Ondas & Turismo \\
\hline Nuvens & Rio & Brasilviagem \\
\hline Pentax & Lago & Pousada \\
\hline Ist & Vivid & Hotéis \\
\hline $\mathrm{D}$ & Praias & Brasil azul \\
\hline $17 \mathrm{~mm}$ & Maragogi fotos & Pousadas em Maragogi \\
\hline Fisheye & Fotos de Maragogi & Miramar Maragogi \\
\hline Brasil & Praia de Peroba & Praia de Maragogi \\
\hline Brazil & Maragogi online & Porto de Galinhas \\
\hline Postal & Aventura & Japaratinga \\
\hline Tamandaré & Galés & Catamarã \\
\hline $\begin{array}{c}\text { Piscinas naturais de Maragogi, } \\
\text { Alagoas }\end{array}$ & Piscinas naturais de Maragogi & Passeio \\
\hline Hotel Salinas & Fotos Maragogi & Referência no Turismo \\
\hline
\end{tabular}

Fonte: elaborado pelos autores.

Um olhar não muito atento é o suficiente para perceber que muitas palavras se repetem em tags diferentes; ainda, percebemos que palavras que deveriam formar uma única tag acabam tornando-se tags distintas, como, por exemplo, CARIBE e BRASILEIRO, seguidas da tag O CARIBE BRASILEIRO.

Aplicando a metodologia de Rodrigues (2007) obtemos: 
Quadro 5-Aplicaçãoda metodologia de Rodrigues (2007) para a Figura 2

\begin{tabular}{|c|c|c|}
\hline DESCRIÇÃO FÍSICA & COMPOSIÇÃO & CONTEXTO ARQUIVÍSTICO \\
\hline--- & Azul & Peroba \\
& Azul turquesa & Alagoas \\
\hline SENTIDO DENOTATIVO & SENTIDOS CONOTATIVOS & TEMATIZAÇÃo \\
\hline Praia & Curiosidade & Turismo \\
Mar & Aventura & Pontos turísticos \\
Céu azul & Férias & \\
Jovens & & \\
\hline
\end{tabular}

Fonte: elaborado pelos autores.

Na tabela comparativa entre as tags consideradas válidas e os termos obtidos teremos:

Quadro 6-Comparaçãoentre as tags consideradas válidas e os resultados obtidos na análise

\begin{tabular}{|c|c|}
\hline$T A G S$ & TERMOS \\
\hline Maragogi & Azul \\
\hline Alagoas & Azul turquesa \\
\hline Peroba & Peroba \\
\hline Praia & Maragogi \\
\hline Mar & Alagoas \\
\hline Céu & Praia \\
\hline Azul & Mar \\
\hline Nuvens & Céu azul \\
\hline Contraste & Jovens \\
\hline Cores & Curiosidade \\
\hline Fortes & Aventura \\
\hline Vibrantes & Férias \\
\hline Viva & Turismo \\
\hline Paraíso & Pontos turísticos \\
\hline$T A G S$ & TERMOS \\
\hline Brasil & --- \\
\hline Postal & --- \\
\hline Ondas & --- \\
\hline Rio & --- \\
\hline Lago & --- \\
\hline Praias & --- \\
\hline Fotos & --- \\
\hline
\end{tabular}




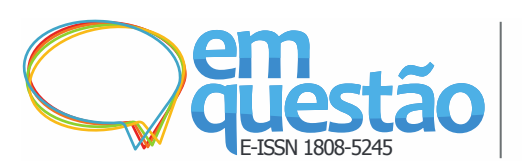

Análise e indexação de imagens na rede Flickr

Rafael Alves de Oliveira, Luciane Paula Vital

\begin{tabular}{|c|c|}
\hline Maragogi & --- \\
\hline Fotos de Maragogi & --- \\
\hline Praia & --- \\
\hline Peroba & --- \\
\hline Caribe & --- \\
\hline Brasileiro & --- \\
\hline O Caribe brasileiro & --- \\
\hline Pousada & --- \\
\hline Hotéis & --- \\
\hline Viagem & --- \\
\hline Dicas & --- \\
\hline Ficar & --- \\
\hline Salinas & --- \\
\hline Boa viagem & --- \\
\hline Brasilviagem & --- \\
\hline Aventura & --- \\
\hline Férias & --- \\
\hline Piscinas & --- \\
\hline Naturais & --- \\
\hline Maceió & --- \\
\hline Turismo & --- \\
\hline Brasil azul & --- \\
\hline Pousadas em Maragogi & --- \\
\hline Praia de Maragogi & --- \\
\hline Porto de Galinhas & --- \\
\hline Japaratinga & --- \\
\hline$T A G S$ & TERMOS \\
\hline Tamandaré & --- \\
\hline Piscinas naturais de Maragogi, Alagoas & --- \\
\hline Piscinas naturais de Maragogi & --- \\
\hline Referência no Turismo & --- \\
\hline Hotel Salinas & --- \\
\hline Catamarã & --- \\
\hline Galés & --- \\
\hline Passeio & --- \\
\hline Fotos Maragogi & --- \\
\hline
\end{tabular}

Fonte: elaborado pelos os autores. 
Com a metodologia de Rodrigues (2007) atribuímos 14 termos a essa imagem, os quais abrangem desde a sua composição, com a cor que notavelmente se destaca, até a sua tematização. Acreditamos ser possível, com esses termos, descrever eficientemente a fotografia e realizar uma recuperação eficiente. As tags consideradas válidas somam 56, dentre as quais oito coincidem com os termos atribuídos. 56poderia ser considerada uma quantidade de termos elevada, especialmente quando comparada com o resultado obtido através da metodologia de Rodrigues (2007). Entretanto, é preciso levar em conta os aspectos conotativos e toda a gama de possibilidades de interpretação que a imagem pode despertar ao observador, de modo que, dependendo do contexto em que o documento seja analisado e representado, um número grande de termos pode ser considerado ideal.No entanto, é necessário estar atento a equívocos na interpretação que poderiam levar a conceituações distantes e passíveis de confusão com outras imagens.Algumas tagsatribuídas à imagem em questão podem exemplificar isso, como é o caso de PORTO DE GALINHAS ou TAMANDARÉ, que são praias localizadas no estado de Pernambuco. Ainda, a tag MACEIÓ refere-se à capital do estado de Alagoas, que não possui relação direta com a fotografia apresentada, o que poderia provocar confusão no momento da busca, visto que esse termo não corresponde corretamente à procedência da fotografia.

Na terceira página de busca encontramos a seguinte imagem:

Figura 3 - Ponte de madeira - Itapuã, RS

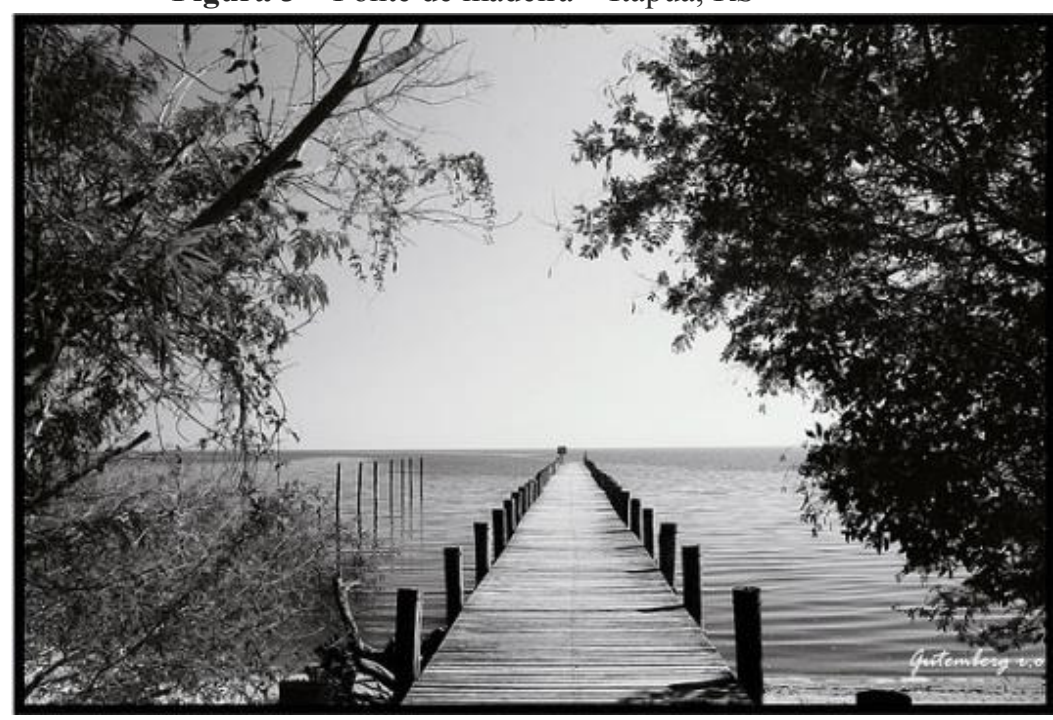

Fonte: Flickr (2014b). 
Nesta imagem temos apenas um panorama, sem a presença de seres humanos. Segundo a descrição do autor, esta fotografia representa uma região da cidade de Itapuã, no Estado do Rio Grande do Sul. As tags atribuídas pelo autor foram:

Quadro 7 - Tags atribuídas à Figura 3 por usuário da rede Flickr

\begin{tabular}{|c|c|c|}
\hline Itapuã & PB & Bem Flickr... Bem Brasil! \\
\hline RS & Noiretblanc & Gutemberg Ostemberg \\
\hline Interior & Bianco & Gutemberg \\
\hline Gaúcho & Nero & Porto Alegre \\
\hline Guaíba & Blanco & Mywinners \\
\hline Rio Grande do Sul & Negro & Bem Flickr... Bem Brasil! \\
\hline BW & Brazil & --- \\
\hline
\end{tabular}

Fonte: elaborado pelos autores.

Mais uma vez percebemos, em INTERIOR e GAÚCHO, palavras que provavelmente deveriam formar uma única tag, mas acabam tornando-se tagsdistintas. Aplicando a metodologia de Rodrigues (2007) obtemos:

Quadro 8-Aplicaçãoda metodologia de Rodrigues (2007) para a Figura 3

\begin{tabular}{|c|c|c|}
\hline DESCRIÇÃO FÍSICA & COMPOSIÇÃO & CONTEXTO ARQUIVÍSTICO \\
\hline--- & Preto e branco & $\begin{array}{c}\text { Itapuã } \\
\text { Guaíba } \\
\text { Rio Grande do Sul }\end{array}$ \\
\hline SENTIDO DENOTATIVO & SENTIDOS CONOTATIVOS & TEMATIZAÇÃo \\
\hline Ponte de madeira & Imensidão & Preservação ambiental \\
Lago & Infinito & Ecossistema \\
Dique & Solidão & \\
\hline
\end{tabular}

Fonte: elaborado pelos autores.

Adotamos 12 termos para representar esta imagem, que buscam englobar tanto o que a imagem mostra, o que ela transmiteaos autores, e os contextos em que pode estar inserida de acordo com a história do local. Itapuã é o nome de uma reserva florestal localizada no município de Guaíba, Rio Grande do Sul. Percebe-se, assim, que alguns destes termos só puderam ser atribuídos porque o autor informa através dos textos onde a fotografia foi tirada. A partir daí o indexador pode investigar o que mais pode ser relevante na sua conceituação, indo além do que a imagem revela. É importante destacar que Lancaster (2004) 
prevê isso em seus estudos, quando aborda as questões relacionadas à indexação de imagens. No quadro comparativo teremos:

Quadro 9-Comparaçãoentre as tags consideradas válidas e os resultados obtidos na análise Fonte: elaborado pelos autores.

\begin{tabular}{|c|c|}
\hline TAGS & TERMOS \\
\hline Itapuã & Preto e branco \\
\hline Interior & Itapuã \\
\hline Gaúcho & Rio Grande do Sul \\
\hline Guaíba & Ponte de madeira \\
\hline Rio Grande do Sul & Lago \\
\hline Negro & Dique \\
\hline Porto Alegre & Infinidão \\
\hline--- & Solidão \\
\hline--- & Guaíba \\
\hline--- & Preservação ambiental \\
\hline--- & Ecossistema \\
\hline--- & \\
\hline &
\end{tabular}

Fonte: elaborado pelos autores.

Dentre as sete tags relacionadas, apenas três coincidem com os termos atribuídos pela metodologia de Rodrigues. Identificamos umasituaçãosemelhante à encontrada na imagem analisada anteriormente, quando se adotou a tag PORTO ALEGRE, referente à capital do Estado do Rio Grande doSul, auma imagem que representa uma localidade situada no município de Guaíba, também no Rio Grande do Sul. No entanto, nesse caso é possível afirmar que, apesar de não haver uma relação direta entre a tag e a localidade apresentada, visto que são municípios diferentes, ainda assim seria admissível reconhecer uma relação relevante, já que o município de Guaíba fica localizado na Região Metropolitana de Porto Alegre.

Até agora analisamos três imagens, sendo que em duas delas não aparecem seres humanos. Cumprindo os procedimentos metodológicos estabelecidos, a última imagem a ser analisada deve necessariamente conter um ser humano. Na quarta página dos resultados de busca encontramos a seguinte imagem: 
Figura 4 - Chapada dos Veadeiros, GO

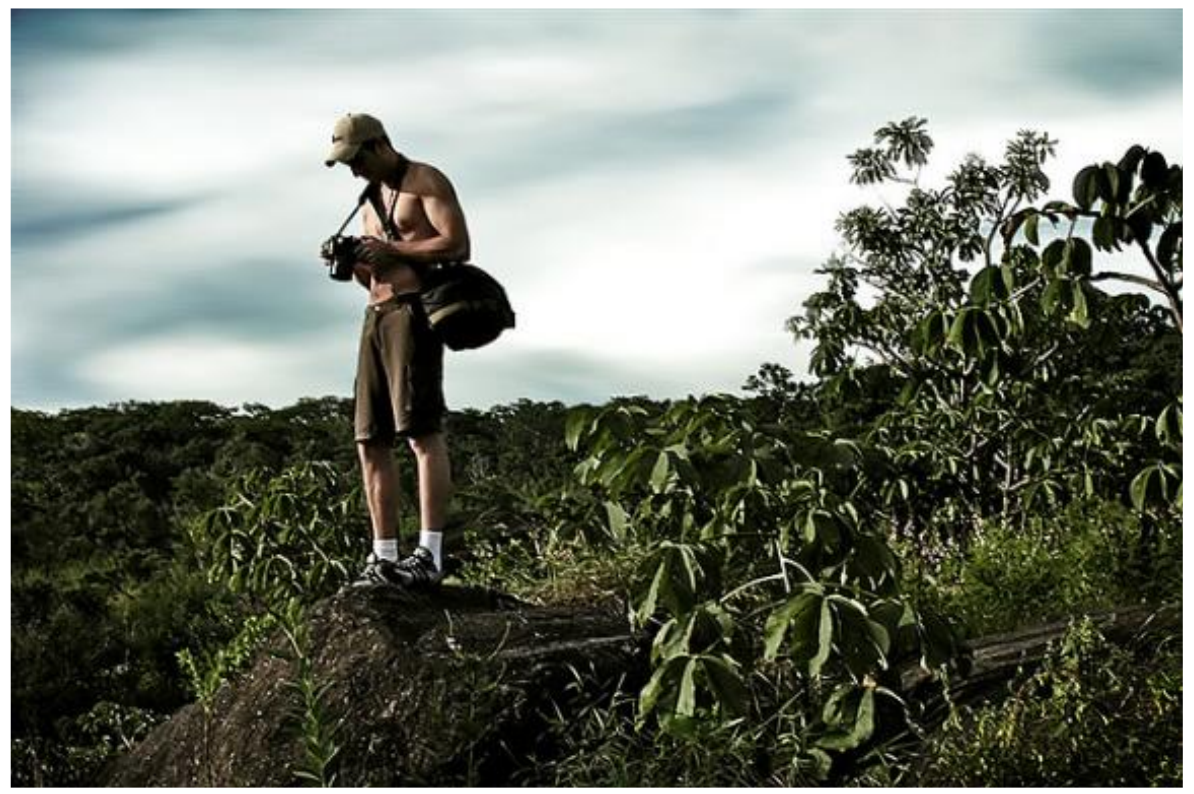

Fonte: Flickr(2014b).

Na imagem há apenas um rapaz com a sua câmera fotográfica em meio a uma imensa paisagem verde. Segundo os textos relacionados à fotografia, ela foi tirada na Chapada dos Veadeiros, localizada no estado de Goiás. As tags atribuídas a essa imagem, diferentemente das outras analisadas, não foram muitas, como relacionado abaixo:

Quadro 10 - Tags atribuídas à Figura 4 por usuário da rede Flickr

\begin{tabular}{|c|c|}
\hline Chapada dos Veadeiros & Eu \\
\hline Vale da Lua & Borguetti \\
\hline Alto Paraíso & Top-v1111 \\
\hline Me & --- \\
\hline
\end{tabular}

Fonte: elaborada pelos autores.

Com a metodologia de Rodrigues (2007), obtemos os seguintes resultados: 
Quadro 11-Aplicaçãoda metodologia de Rodrigues (2007) para a Figura 4

\begin{tabular}{|c|c|c|}
\hline DESCRIÇÃO FÍSICA & COMPOSIÇÃO & CONTEXTO ARQUIVÍSTICO \\
\hline--- & Verde & $\begin{array}{c}\text { Chapada dos Veadeiros } \\
\text { Goiás }\end{array}$ \\
\hline SENTIDO DENOTATIVO & SENTIDOS CONOTATIVOS & TEMATIZAÇÃO \\
\hline $\begin{array}{c}\text { Floresta } \\
\text { Homem }\end{array}$ & Aventura & $\begin{array}{c}\text { Pontos turísticos } \\
\text { Ecossistema }\end{array}$ \\
\hline
\end{tabular}

Fonte: os autores

$\mathrm{Na}$ tabela comparativa, considerando os critérios determinados anteriormente para a validade das tags, teremos:

Quadro 12-Comparaçãoentre as tagsconsideradas válidas e os resultados obtidos na análise

\begin{tabular}{|c|c|}
\hline TAGS & TERMOS \\
\hline Vale da Lua & Verde \\
\hline Alto Paraíso & Chapada dos Veadeiros \\
\hline Eu & Goiás \\
\hline Chapada dos Veadeiros & Horesta \\
\hline--- & Homem \\
\hline--- & Lventura \\
\hline--- & Pontordade \\
\hline--- & Ecossistema \\
\hline--- & \\
\hline
\end{tabular}

Fonte: elaborado pelos autores.

A Chapada dos Veadeiros é uma vasta região que abrange diversos municípios, dentre eles Cavalcante, Alto Paraíso de Goiás e Teresina de Goiás. Possivelmente por isso o autor atribuiu a tag ALTO PARAÍSO, referindo-se ao município em que, talvez, localizava-se no momento da fotografia. No entanto, sendo este termo específico demais, não foi considerado na sua análise. Da mesma forma, VALE DA LUA refere-se a uma região específica da Chapada dos Veadeiros, mas que não é possível identificar nem na descrição textual, nem na imagem em si. Assim, consideramos apenas o termo genérico CHAPADA DOS VEADEIROS. Nesse sentido, apenas uma tag coincidiu com os termos atribuídos na análise, que foram nove no total.

Sobre a análise qualitativa de dados, podemos fazer uma breve comparação entre os termos e as tags, e verificar como os dados que obtivemos 
nas análises se comportam. Todas as tagsatribuídas às quatro imagens analisadas e consideradas válidas somam o total de 83 , enquanto os termos adquiridos por meio da metodologia de Rodrigues (2007) somam 43. Do total de tags, apenas 16 coincidem com o total de termos, o que resulta em aproximadamente 39,02\% de compatibilidade entre as tags e os termos.

Além disso, analisando as tabelas comparativas podemos perceber que, em geral, os termos que coincidiram foram apenas os que dizem respeito à localização geográfica do ponto em que a fotografia foi tirada, o que não garante uma riqueza na conceituação por meio das tags.

Observamos neste estudo, também, que é essencial para o indexador identificar e considerar os diversos aspectos que uma imagem pode conter. Durante as análises, percebemos que as imagens coletadas possuem a maior parte das características propostas por Rodrigues (2007) como sendo as mais relevantes. No entanto, à exceção dos termos PASSEIO, FÉRIAS, PARAÍSO, TURISMO e REFERÊNCIAS NO TURISMO (Figura 2), que remetem à tematização da imagem, não encontramos nenhuma tag que correspondesse a elementos conotativos ou temáticos, e poucas as tags correspondentes a elementos denotativos. Entende-se, assim, que não há um equilíbrio entre os tipos de elementos descritos, sendo esses predominantemente relativos à sua composição e ao seu contexto arquivístico (RODRIGUES, 2007).

\section{Considerações finais}

Apesar da baixa qualidade identificada na indexação realizada por meio das tags, o valor da indexação social não se perde. $\mathrm{O}$ fato de existirem ferramentas capazes de permitir esse tipo de atividade representa um avanço significativo na forma como os novos profissionais da informação devem encarar a representação da informação, seja ela imagética ou não. Alguns estudos inclusive já apontam para propostas de metodologias para a atribuição das tags (HIDDERLEY; RAFFERTY, 2007). Isso remonta, de alguma forma, aos estudos iniciais de Panofsky (1979) sobre a conceituação de imagens. Os conceitos iniciais evoluíram de tal forma que hoje somos capazes de analisar 
minuciosamente imagens disponibilizadas em ambiente web, algo impensável algumas décadas atrás. É possível que, em alguma medida, estejamos no mesmo marco inicial em que se encontrava Panofsky (1979) quando iniciou o estudo sobre essas questões.

Ao lado de grandes ferramentas da Web 2.0, como a Wikipedia, por exemplo, o Flickr faz cada vez mais parte do cotidiano de nossa sociedade. No entanto, as possibilidades advindas dessa evolução e a velocidade com que essa ocorreu e ainda ocorre requerem dos profissionais estudos frequentes para compreender a usabilidade e os potencializar os mecanismos dessas novas ferramentas.

A indexação de imagens é uma atividade complexa e altamente passível a interpretações e questionamentos diferenciados. Devido a isso, foi necessário fazer um estudo aprofundado sobre o tema através da literatura existente, para entender realmente a problemática e buscar um embasamento científico para analisar qualitativamente as imagens.

Buscamos, a partir desse estudo, criar uma reflexão em torno das problemáticas que estão surgindo no ambiente de tratamento, organização e disseminação da informação. Por mais que diversos estudos proponham formas de tratamento de imagens, é preciso estar atento à eficiência desses métodos em ambientes que não sejam restritos a bibliotecas e centros de documentação.

\section{Referências}

FLICKR. Ajuda: tags. 2014a. Disponível em: $<$ http://www.flickr.com/help/tags/\#37>. Acesso em: 15 out. 2014.

FLICKR. Busca de imagens.2014b. Disponível em:

$<$ http://www.flickr.com/search>. Acesso em: 15 out. 2014.

FLICKR. Sobre o Flickr. 2014c. Disponível em:

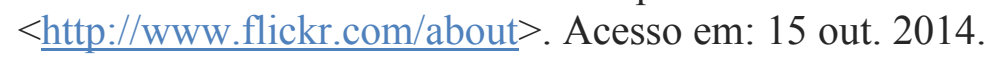

GIL, Antônio Carlos. Métodos e técnicas de pesquisa social. 6. ed.São Paulo: Atlas, 2008. 
GUEDES, Roger de Miranda; DIAS, Eduardo José Wense. Indexação social: abordagem conceitual. Revista ACB: Biblioteconomia em Santa Catarina, Florianópolis, v. 15, n. 1, p.39-53, jan./jun. 2010.

HIDDERLEY, R.; RAFFERTY, P. Flickr and democratic indexing: dialogic approaches to indexing. Aslib Proceedings, London, v. 59, n. 4/5, p. 397-410, 2007. Disponível em: $<$ www.emeraldinsight.com/0001-253X.htm $>$. Acesso em: 11 jan. 2012.

LANCASTER, F. W. Indexação e resumos: teoria e prática. 2. ed. Brasília: Briquet de Lemos, 2004.

MANINI, Miriam Paula. Análise documentária de fotografias: um referencial de leitura de imagens fotográficas Para fins documentários. São Paulo, 2002. Tese (Doutorado em Ciências da Comunicação) - Departamento de Biblioteconomia e Documentação, Escola de Comunicações e Artes, Universidade de São Paulo, São Paulo, 2002.

OLIVEIRA, Rafael Alves de. Metodologias para indexação de imagens fotográficas em ambiente web. In: ENCONTRO DE ESTUDOS SOBRE TECNOLOGIA, CIENCIA E GESTÃO DA INFORMAÇÃO. Anais.... Recife: -Universidade Federal de Pernambuco, 2011. 1 CD-ROM. .

PANOFSKY, E. Significado nas Artes Visuais. 2. ed. São Paulo: Perspectiva, 1979.

RODRIGUES, Ricardo Crisafulli. Análise e tematização da imagem fotográfica. Ciência da Informação, Brasília, v. 36, n. 3, p. 67-76, set./dez. 2007.

\title{
Analysis and index of images on Flickr network
}

\begin{abstract}
This article presents a brief overview on the dissemination and democratization of the collaborative web, and how this process popularized the use of the image in digital form. A brief analysis of the Flickr social network, identifying their goals, tools, and some studies on its usability in the context of information science. Sets out the approach to the images stored on the network, proposing a qualitative study about the free indexing performed by users. Applies the methodology established in a previous study as the most appropriate
\end{abstract}


for indexing images in a web environment, comparing the results obtained with free indexing performed by users.

Keywords: Image. Indexing of images. Flickr. Social networks. Social indexing.

${ }^{1}$ No original: "The [...] tag [...] "wedding" retrieved 795.280 images, when it was used on Flickr on 14 February 2006, which suggests that this an example of a tag that is perhaps too broad. The $[\ldots]$ tag "Iijsselmeer" only retrieved one image and is an example of a tag that is perhaps too specific for public searching purposes".

Recebido: $16 / 10 / 2014$

Aceito: 01/04/2015 